\title{
Artelogie
}

artelogie Recherche sur les arts, le patrimoine et la littérature de l'Amérique latine

$6 \mid 2014$

Horizons et dispositifs des arts plastiques des pays du Río de la Plata (XXe siècle)

\section{Joaquín Torres-García: a arte como lugar da utopia e do mito}

Texto elaborado o catálogo da Exposição "Joaquín Torres Garcia.

Geometria, Criação, Proporção", Fundação Iberê Camargo, 2011.

\section{Maria Lúcia Bastos Kern}

\section{(2) OpenEdition}

\section{Journals}

Edición electrónica

URL: http://journals.openedition.org/artelogie/1428

DOI: 10.4000/artelogie. 1428

ISSN: 2115-6395

Editor

Association ESCAL

Referencia electrónica

Maria Lúcia Bastos Kern, " Joaquín Torres-García: a arte como lugar da utopia e do mito », Artelogie

[En línea], 6 | 2014, Publicado el 29 junio 2014, consultado el 01 mayo 2019. URL : http://

journals.openedition.org/artelogie/1428; DOI : 10.4000/artelogie.1428

Este documento fue generado automáticamente el 1 mayo 2019.

Association ESCAL 


\section{Joaquín Torres-García: a arte como lugar da utopia e do mito}

Texto elaborado o catálogo da Exposição "Joaquín Torres Garcia. Geometria, Criação, Proporção", Fundação Iberê Camargo, 2011.

\section{Maria Lúcia Bastos Kern}

"A atividade criativa do homem se situa como um dos meios de controle do sentido, e por consequência uma das condições de sua liberdade." Philippe Sers

'Tinha que ordenar esse mundo que agora, parecia um caos.' Torres-García

1 O artista moderno, ao aspirar revolucionar os sentidos de arte e de mundo, enfrenta a necessidade de criação da obra autônoma, independente da literatura e das representações naturalistas, com objetivo de elaborar novas linguagens formais e meios expressivos. Consciente de seu papel como agente social e de sua liberdade, ele faz experimentações e vivencia um processo conflituoso e solitário, para transgredir o convencional, criar formas, que julga puras, e seus princípios para submetê-los à sociedade, como portadores de verdade e de conteúdo universal. A obra é concebida como conhecimento e testemunho das etapas de pesquisa, juntamente, com os textos explicativos, que evidenciam os questionamentos, as reflexões e as experiências vivenciadas pelos artistas que investem em novos projetos com propósitos éticos. Eles planejam o futuro ao acreditarem que a arte tem a potencialidade de transformar o mundo moderno, conturbado por permanentes crises, e repor a ordem.

2 O Construtivismo de Torres-García integra-se nessa projeção utópica motivada por uma personalidade inquieta e idealista, inconformada com o materialismo e a ausência de espiritualidade. A nova prática artística começa no momento em que vive em Paris (1926-32), após longos períodos de pesquisas e de indagações. As suas obras e textos reflexivos revelam o percurso exploratório efetuado para construção de uma arte, programada para se tornar acontecimento e mecanismo de intervenção social. 
3 As experimentações são efetuadas em desenhos, pinturas, objetos tridimensionais e pequenos livros, nos quais ele expressa, por meio de pictografias, suas reflexões a respeito do próprio processo de criação. Essas atividades são concomitantes e iniciadas durante a sua estadia em Barcelona (1892-1920), apesar de a historiografia ter enfatizado o contato em Paris com Theo Van Doesburg (1928) e Piet Mondrian (1929) como motivador das mudanças de sua linguagem. Esses artistas são importantes para o amadurecimento de suas pesquisas, mas não é possível ignorar o processo anterior de elaboração prática e de formulação de conceitos.

4 Algumas ideias norteadoras do Construtivismo são concebidas antes das mudanças de sua obra e da criação dos brinquedos (1917) para a indústria. ${ }^{1}$ Esses objetos tridimensionais são construídos por formas sintéticas, em madeira policromada, enquanto os desenhos e as pinturas revelam a utilização de conceitos, tais como estrutura e plasticidade, oriundos da concepção de autonomia da arte, da forma e da cor como valores próprios (Notes d'Art 1913). A pintura começa a se transformar a partir de 1916, quando acentua o desenho geométrico e configura o espaço, reduzindo-o às figuras e aos planos em movimentos, sugeridos pelo dinamismo da vida moderna na cidade.

5 Essas mudanças se produzem depois de um período em que Torres-García se vincula ao programa nacionalista de Eugenio D'Ors, o Novecentismo (1906), porém com um projeto estético próprio, o Mediterranismo, ${ }^{2}$ direcionado ao resgate das raízes culturais grecoromanas da Catalunha. Ele executa grandes pinturas murais para o palácio governamental e retoma recursos artesanais e técnicas de afresco em desuso, que são utilizados para representações de alegorias de caráter universal, porém com intenções de conectar com a cultura e a paisagem locais. ${ }^{3}$ Nesse momento, a sua pintura expressa ainda as singularidades dos costumes e das atividades econômicas, cujas formas sintéticas de cores intensas transcendem a realidade e são dotadas de certos arcaísmos originados pelas pesquisas efetuadas nos afrescos da antiguidade e do quatrocento florentino. A admiração pela obra de Puvis de Chavannes também o estimula à síntese formal e à simplicidade primitiva, porém sem deixar de consagrar os valores intemporais clássicos e a ordem em oposição à desordem, que acredita reinar nas artes e na civilização modernas. ${ }^{4} \mathrm{~A}$ retórica presente nos murais oficiais evidencia o exemplo de um passado idealizado para a nova Catalunha e a convicção de que o artista é um homem superior que percebe o mundo com maior clareza. []

6 Apesar da conotação ideológica e de fins éticos, a sua pintura é realizada após uma série de estudos e sempre acompanhada pela publicação de textos reflexivos e por trabalhos decorativos e gráficos para revistas e cartazes. A pluralidade de atividades, o recorrente questionamento relativo às suas práticas e à arte moderna, bem como a insatisfação com a política catalã possibilitam a Torres-García dar um novo rumo à sua obra e ao processo de pesquisa. ${ }^{6}$

7 A cidade o fascina e proporciona novas percepções a respeito das noções de espaço e tempo. Torres-García é sensível aos signos modernos, à velocidade e ao fluxo incessante das mudanças em Barcelona ${ }^{7}$ e, depois, em Nova Iorque (1920-22) e Paris (1926-32). A publicidade, a arquitetura, a multidão, os luminosos, os meios de transporte, o relógio compõem as pinturas e os desenhos, cujas formas, de colorido intenso, são fragmentadas, sobrepostas e dispostas num movimento simultâneo. Elas são, muitas vezes, articuladas por retículas que compõem a estrutura geométrica, pela introdução de palavras e números, em caixa alta, que se integram ao cenário urbano, e identificam as cidades e os bairros, como se pode observar em New York City (1920). ${ }^{8}$ As formas geométricas e planas 
estão mais presentes, como Escena de calle de Barcelona (1917); ou as amplas perspectivas que destacam as grandes avenidas e seus arranha-céus. É uma 'pintura de ritmos livres, porém já com domínio de vertical e horizontal', signos que auxiliam na ordenação e na elaboração da linguagem plástica. ${ }^{9}$ Essas pinturas, ao celebrarem o moderno, revelam o afastamento temporário do primitivo e a preocupação do artista com a síntese formal e a prática de conceitos, que são divulgados em publicações (1907-1922) ${ }^{10} \mathrm{e}$ importantes para o andamento do processo criativo.

8 Na Europa, Torres-García dá continuidade às experiências formais em diferentes suportes e categorias, inclusive nos brinquedos, porém sem abandonar a temática da cidade. Ele intensifica os estudos relativos às artes primitivas, ao identificar nelas a solução para estancar a decadência da arte moderna e a sua carência espiritual. A criação da nova linguagem materializa-se, inicialmente, nos objetos tridimensionais e, posteriormente, na pintura. Em paralelo, elabora pequenos livros (1928), cujo texto não cursivo é complementado por pictografias, construídas por formas sintéticas como nas pinturas.

Os livros constituem-se como pequenos objetos escritos à mão e desenhados, em que as capas se compõem por formas geométricas e/ou por colagens, sendo a brochura, em certas ocasiões, costurada com cordão rústico, deixando visível o seu processo artesanal e primitivo, que remete aos momentos que antecedem a descoberta da impressa e à sua resistência à produção mecânica.

10 A relação texto e imagem é constante, quando ele se afasta da representação e da narrativa e introduz na pintura formas geométricas e símbolos, estabelecendo relações internas entre as partes, na busca de efeitos de conjunto e de invenção de sintaxe. TorresGarcía considera o símbolo como uma ideia gráfica que constitui a linguagem, na qual ler e ver se conectam numa mesma obra. Em Ce que je sais et ce que je fais par moi-même (1930), ele declara: "As palavras são um convencionalismo que nós inventamos para nos comunicar. As letras do alfabeto e o desenho também (...). Todo mundo pode se exprimir, (...) por esse meio gráfico (...) uma forma de grafismo geométrico". Ao realizar a primeira pintura construtiva, ele percebe que teria que "ordenar (aquelas ideias gráficas)", "deveria compreender o que havia feito, deveria estudar sua própria obra (...)." 11

11 Os livros e as obras assumem o papel de testemunhos das experiências em curso, das indagações, dos avanços e dos problemas vivenciados pelo artista, de seus conceitos e suas percepções de mundo.

12 No clima de crise europeia do pós 1․ Guerra Mundial, das vanguardas e do próprio homem, em que predomina o espírito de regeneração e de construção, a forma geométrica representa o sentido de ordem/estabilidade e, ao mesmo tempo, é, segundo a visão de Torres-García, expressão metafísica. Ele, ao negar a representação ilusionista, especula outra realidade, tendo como objetivo descobrir o caminho para um mundo superior, de ordem espiritual. No entanto, não abandona completamente a figuração como propuseram os artistas abstratos e construtivistas, mas busca o absoluto através das formas sintéticas e dos símbolos.

13 Ele acredita que a abstração corresponde à ideia de alguma coisa e que a solução se encontra "no figurado graficamente" ou no "nome escrito da coisa, ou uma imagem esquemática, o menos aparentemente real possível : tal como um signo." ${ }^{12}$. Para TorresGarcía, o essencial é a estrutura ortogonal que termina com a hierarquia figura/fundo, em prol da construção geométrica e da ordem. Assim, as suas imagens preservam o 
referencial e constituem-se como símbolos, permeados por convicções místicas e éticas, presentes também nos textos e nos conceitos de arte.

14 A preocupação espiritual não é um caso isolado, mas relativamente comum entre artistas modernos, cujas projeções utópicas prevêem que as suas obras sejam promotoras de mudanças, face à "morte de Deus" e à excessiva valorização da ciência, do progresso e da matéria na modernidade. Vários artistas, desde o Simbolismo, acreditam que é necessário programar um devir espiritual, distinto das religiões institucionalizadas. ${ }^{13}$ Eles são sensibilizados pela Teosofia e outras crenças, que paralelo às invenções de novas linguagens formais, os estimulam a expressar a espiritualidade. Conscientes do papel a ser exercido, artistas como Torres-García, praticam discursos em que misturam experiências estéticas com questões espirituais e éticas. Ao afastarem-se do naturalismo, identificado como positivista, eles elaboram verdadeiras gramáticas de signos e princípios de utilização das linhas, das cores, da luz e dos sons, que permitem a produção de uma semântica visual, num momento em que a linguística também exerce grande colaboração.

Alguns artistas adotam a noção de estrutura da teoria da Gestalt, que a conceitua como a própria forma de organização de elementos, os quais só adquirem significados enquanto partes do todo ordenado. Se até o século XX, ela era oculta na obra, nesse momento passa para a superfície, de modo aparente, e estabelece a unidade na conjunção da diversidade. Segundo Philippe Sers, a proposta de unidade para estabelecer a ordem revela a liberdade que os artistas dispõem para fazerem intervenções coletivas, direcionadas ao devir. ${ }^{14}$

Na obra de Torres-Garcia, a unidade e a ordem são formalizadas pela estrutura, contra a representação fenomênica da realidade, sendo esta efetuada, em geral, pela regra de ouro, para possibilitar o maior controle da subjetividade. A estrutura ortogonal (1930) é construída formando nichos geométricos, nos quais insere símbolos de origem arcaica, que são classificados, segundo sua concepção mística do universo. Em Raison et Nature (1932), ele os ordena em três planos - intelectual, moral e físico - representados respectivamente pelo triângulo, coração e peixe que, a seu ver, constituem o cosmos e se relacionam entre si. Esses símbolos são recorrentes e, muitas vezes, dispostos nas pinturas de baixo para cima, conectados pela escada e pela flecha, em ascensão do mundo natural (peixe) aos mundos intelectual (triângulo) e espiritual (sol). Ele justifica que o plano superior exerce o papel de dominação soberana ao impor a regeneração, por meio da ordem e do controle aos demais. Gilbert Durand ${ }^{15}$ verifica nos símbolos ascensionais ligações com as atitudes morais e metafísicas e identifica a escada como resistência ao tempo e à morte. A tradição da imortalidade, praticada por ameríndios e outros grupos étnicos, é também cultivada pelos cristãos, por meio do dualismo, e contra a queda.

17 Torres-García apropria-se de símbolos de distintas procedências e regulamenta nos textos os seus significados de modo rigoroso. Entretanto, nas suas obras as disposições e associações simbólicas são variadas e não expressam sempre as mesmas acepções, fato que as tornam manifestações subjetivas e do sentido misterioso da existência e do sagrado. Segundo Pierre-Henry Frange, ${ }^{16}$ o símbolo apresenta uma tríplice vocação cósmica, onírica e poética para suprir o desejo de unidade viva do mundo e da obra. As redes de relações simbólicas presentes nas suas pinturas não são sempre apreendidas na sua integralidade, deixando espaço para o enigma e revelando o seu pensamento mítico, produzido na ideia de totalidade e do mundo em sua unidade. 0 mito é produzido por meio de símbolos, compostos por um pensamento-imagem, dotado de autonomia e pelo caráter de ambiguidade e mistério que lhes são próprios. 
18 A linguagem de Torres-García configura-se também no dualismo ao se compor nas oposições horizontal/vertical, material/espiritual, arcaico/moderno, universal/ particular, para concretizar a unidade, que acredita constituir o universo. No livro Père (1931), ele justifica que "o princípio de unidade é também a lei que rege o universo (...). Tudo isto vem de Deus. Nós estamos presos a ele, espiritualmente". Seu pensamento e obra expõem o fenômeno verificado por Jung, relativo à dificuldade de o homem descrever a entidade divina e à necessidade de elaborar símbolos na tentativa de representar conceitos que não consegue compreender integralmente. ${ }^{17}$

Num manuscrito, contemporâneo à expansão do Surrealismo, Décadence et primitivisme (1928), o artista declara: "Estamos num momento da história em que é necessário ser primitivo ou decadente, espiritualista ou realista. Podemos ser os primitivos de outra grande época (...)." Como os intelectuais da revista Documents (1929-31), Torres-García critica os artistas pela utilização formal das artes primitivas sem considerar as suas funções rituais, espirituais e a integração da linguagem com o universo. Para o uruguaio, a forma geométrica permite conduzir à "eurritmia, como os selvagens", a "expressar mediante os símbolos" o "nascer de um novo mundo de coisas e formas." Carl Einstein ${ }^{18}$ observa o interesse entre os artistas pelas forças criativas arcaicas, que durante muito tempo foram neutralizadas pelo excesso de racionalidade e de normatização. Ele considera esse momento como uma espécie de "intervalo romântico", que possibilita ao artista entrever outras formas e construir outra realidade.

Em Montevidéu (1934), Torres-García denomina a nova arte de Universalismo Constructivo, e justifica que a geometria e os símbolos são universais e expressam uma ordem superior que rege o cosmos. Nesse momento, ele intensifica o estudo das artes pré-colombianas, sobretudo andinas, e o projeto de implantação do Universalismo Constructivo em toda a América, propondo uma arte religiosa e monumental, que tenha dimensão coletiva e estimule todo o homem à espiritualidade. Para ele, a arte religiosa e social é de todas as épocas e é a afirmação da verdade e do Homem Universal. "Por isto, pertencemos à grande tradição, ao grupo dos construtores." ${ }^{19}$ Torres-García assume a missão utópica de concretizar a transformação estética e social da América, a partir da integração da arte na vida e dos povos numa sociedade promissora e independente da cultura europeia.

21 Diante da crise da sociedade moderna, ele pensa que a solução se encontra na cultura ameríndia, na qual a espiritualidade era incorporada à arte e permitia a ordenação social. As suas projeções direcionadas à regeneração e à purificação, no contexto do Universalimo Constructivo, compõem a utopia de superação dos fenômenos que motivaram a crise e, ao mesmo tempo, a salvação das culturas e das sociedades no Novo Mundo, afastadas dos problemas inerentes à colonização e à modernidade. Como a ciência e a religião, a arte deveria aspirar ao universal e ser portadora de verdade e de positividade em relação ao devir.

22 A obra de Torres-García evidencia o seu pensamento idealista pautado no conceito de unidade como princípio original, que tem como missão impor a ordem e a espiritualidade. A obsessiva busca de ética permeia os seus discursos e as suas práticas artísticas, desde o Mediterranismo, sendo a mesma configurada por uma rede de distintas memórias e temporalidades, oriundas dos mitos, das formas e dos símbolos arcaicos, do clássico e do moderno. No Universalismo Constructivo o artista articula essas reminiscências e cria nova linguagem, porém sem deixar de marcar as singularidades das culturas tradicionais da América. "Essa tradição pode nos levar ao que é perfeito, estando equilibrado sobre o que 
é imutável" ${ }^{20}$ e concretizar a prática de valores éticos, universais, eternos e modernos, por meio da arte e da formação de discípulos, que evidenciam o artista na sua integridade.

\section{NOTAS}

1. Os brinquedos evidenciam a convicção de que a arte não deve continuar divorciada da vida. Em 1913, Torres-García cria em Sarriá uma Escola de Decoração com esse objetivo.

2. O Mediterranismo e o Novecentismo inserem-se em um movimento nacionalista, liderado pelas elites políticas e intelectuais, que formulam programas de construção da cultura nacional e de modernização da Catalunha, em oposição à política centralizadora do Estado espanhol e à perda de parte de suas colônias. O repúdio político estende-se a outros segmentos após a "Semana Trágica"(1909), quando a população se revolta contra a manutenção da guerra no Marrocos e as perdas humanas, sendo grande parte do contingente de militares recrutados em Barcelona. Essa convulsão estimula a coesão social em prol da autonomia. KERN, M.L. As invenções da paisagem na modernidade. In : BULHÕES, M.A. ; KERN, M.L. Paisagem Desdobramentos e Perspectivas Contemporâneas. Porto Alegre:UFRGS, 2010. p.125-6.

3. Para o artista, "conviria (...) por em marcha a formação de uma arte superior, bem nossa desligada da influência estrangeira (...) mas plena do espírito que perdura em nossa raça, e plena de luz cálida do nosso mar e nossas montanhas." Notes sobre Art, 1913.

4. O movimento em prol da valorização da arte do Mediterrâneo emerge também na França e na Itália, sendo em parte motivado pela oposição às artes nórdicas europeias e às suas concepções pejorativas face às outras modalidades de expressão.

5. TORRES-GARCÍA, J.La nostra ordinación (1907).

6. No livro El descubrimiento de sí mismo (1917), Torres-García apresenta um discurso a respeito da modernidade e do individualismo em arte, que denota o abandono do ideal nacionalista e a revisão de suas ideias e práticas artísticas, motivando-o a declarar a necessidade de esquecer 'o passado para ir à felicidade em direção ao desconhecido (...). o presente é nosso, para poder fazer coisas dignas de virtude. O futuro é a promessa de algo desconhecido que seria belo descobrir.'

7. "Há dois passos daqui uma rua ; um formigueiro de gente que se cruza em direção oposta e se perde em mil ruas, que se unem com outras mil. A nossa cidade (...) com o seu porto. Agora, acabo de descobri-la, como é bela'.

8. Em Nova Iorque, Torres-García se deslumbra : 'Que vida! Que movimento! tudo é mecânico, ordenado, limpo (...)! Esta é a civilização (...). Oh, que velha e triste é a Europa !' Historia de mi vida. (1939) Barcelona : Paidós, 1990. p. 151.

9. TORRES-GARCIA, J. Historia de mi vida. Opus Cit., p.151.

10. La nostra ordinación el nostre camí (1907); Notes sobre art (1913); Dialegs (1914); Un ensayo de clasicismo (1916) e vários artigos em periódicos.

11. TORRES GARCIA, J.Historia de mi vida. Opus Cit, p 211.

12. TORRES GARCIA, J. Historia de mi vida. Opus Cit, p. 210-11. Ele não diferencia signo de símbolo.

13. COURT, R. La verité de l'art ? Paris : Eremé, 2003. p. 151-2.

14. SERS, P. L'Avant-garde radicale. Paris : Les Belles Lettres, 2004. p. 101.

15. DURAND, G. As estruturas antropológicas do imaginário. São Paulo: Martins Fontes, 1997. p. 126-7.

16. FRANGE, P.H. La négation à l'oeuvre. Rennes : Presse Universitaire de Rennes, 2005. p. 110. 
17. JUNG, C. O homem e seus símbolos. Rio de Janeiro : Nova Fronteira, 1964. p. 21.

18. MEFFRE,L. Introduction In : EINSTEIN, C. Georges Braque. Bruxelles : Le Part de l'Oeil, 2003. p. 8

19. TORRES-GARCÍA, J. Universalismo Constructivo. Madri : Alianza Editorial, 1984. p. 501.

20. Torres-García, J.Raison et Nature (1932) 